\title{
Siblings of children with cancer-the price they pay to function
}

\author{
Andreas Guggemos ${ }^{1,3}$ - Florian Juen ${ }^{2} \cdot$ Lina Engelmann ${ }^{2}$. \\ Viola Diesselhorst ${ }^{3}$ - Günter Henze ${ }^{3}$. Alain Di Gallo ${ }^{4,5}$
}

Received: 7 November 2014 / Accepted: 23 March 2015 / Published online: 28 April 2015

(C) Springer-Verlag Berlin Heidelberg 2015

Keywords Siblings $\cdot$ Children $\cdot$ Cancer $\cdot$ Coping $\cdot$ SDQ . MSSB

When a child is diagnosed with cancer, this might generate an existential crisis and the emotional balance of the entire family is deeply disturbed. This is also because parental attention, worries and care strongly focus on the sick child. When there are siblings, there is no doubt that they are also in need of their parents' care and attention to adjust to this challenging situation. Being exposed to cancer increases the risk of adverse mental reactions in combination with other risk factors such as low social support, pre-existing adjustment problems or parental mental disease. Empirical findings regarding quality, quantity and intensity of specific reactions of siblings to a cancer diagnosis are inconsistent. Whereas some researchers point to a higher prevalence of psychopathology, such as

Andreas Guggemos and Florian Juen contributed equally to this work.

Alain Di Gallo

alain.digallo@upkbs.ch

1 Department of Pediatric Oncology/Hematology, Children's Hospital Cologne, Amsterdamerstraße 59, 50735 Cologne, Germany

2 Institut of Psychology, University Innsbruck, Innrain 52, 6020 Innsbruck, Austria

3 Department of Pediatric Oncology/Hematology, Charité Universitaetsmedizin Berlin, Augustenburger Platz 1, 13353 Berlin, Germany

4 University Clinic of Child and Adolescent Psychiatry, Basel, Switzerland

5 Kinder- und Jugendpsychiatrische Klinik, Universitäre Psychiatrische Kliniken (UPK) Basel, Schaffhauserrheinweg 55, 4058 Basel, Switzerland behavioural and mood disorders or impaired development among these children, others do not report any abnormalities at all [1-3]. These heterogenous findings are likely to be due to the diversity of accompanying risk factors, as well as to different times and intervals of assessment. Further reasons might be the diversity of (a) research methods (questionnaires vs. interviews), (b) dimensions observed (behavioural outcome vs. intrapsychic effort) or (c) the sources of information (self vs. proxy rating). Questionnaires provide adequate behavioural screening; however, when used as a single measure, they may not always be sufficiently sensitive in assessing subjective and affective dimensions. With questionnaires alone, we might underestimate aspects of the burden siblings suffer from and not be able to detect precursors of maladaptive development. For this reason, we advocate the use of complementary assessment methods in order to study siblings' specific intrapsychic reactions and adjustment to this challenging experiences. In child and adolescent psychiatry and psychosomatic medicine, we use child's play as a valuable source of information about the child's inner world. The Mac Arthur Story Stem Battery (MSSB) is a standardized self-report measure designed to assess the intrapsychic strain and conflicts of children [4]. By acting out the beginnings of conflictual stories, the interviewer seeks to generate emotional tension within the child. Once the interviewer has told the beginning of the story, the child is asked to continue it and to show and tell what happens next. The narration and the way the child plays with the figurines provide insight into its inner world, its fears and wishes $[5,6]$. The child's stories also yield information about how it deals with present problems. As we know from other studies, the MSSB is sensitive to intrapsychic changes even weeks or months before behavioural outcomes are observed using questionnaires [7].

In the present study, we compared 14 siblings of children diagnosed with cancer ( 7 girls, 7 boys) with a matched control 
group of 18 children ( 9 girls, 9 boys). Children's ages ranged from 6 to 12 years. Siblings of children with cancer were interviewed 2 weeks after the cancer diagnosis (time 1) and 2 weeks after the end of therapy (time 2). We also asked parents to fill in the Strengths and Difficulties Questionnaire (SDQ) [8], a behavioural diagnostic screening tool that measures psychopathological symptoms in children. Our control sample was assessed using the same method and with a time interval of 6 months. An extensive description of the methods and results of this study can be found elsewhere [9]. In this commentary, we aim to discuss the specific challenges of siblings of children with cancer in terms of intrapsychic efforts to adjust that are not directly observable on a behavioural level. An important result of our study was that we found no differences in the questionnaire-based measures (SDQ) between the affected group and the control group and between the two times of assessment in either group, whereas significant differences and changes did emerge in the play assessment method (MSSB). In our sample, the affected siblings coped well on the behavioural level within the 6-month time period. At both assessments, the SDQ mean scores on the total difficulties scale of all participants were far below the clinical cut-off. In the MSSB narratives, at time 1, we found significantly more themes (topics arising in the narratives) in the stories of the affected children compared with those of the controls. The siblings of children with cancer more often displayed themes of morality (like guilt or shame), avoided displaying interpersonal conflicts, showed problems in keeping the characters and situations regulated (themes of dysregulation) and even showed significantly more elements of magic disruptions, destruction and threat (themes of dissociation). In other studies $[10,11]$, these last three elements have been shown to be highly predictive of later psychopathological outcomes. In addition, the affected group showed a tendency to manipulate and control the situation and the interviewer by changing the rules of play, which might reflect their confusion and fear of losing control over the course of the story. In summary, we have evidence that shortly after the cancer diagnosis, the siblings showed clear reactions of intrapsychic adjustment that may hold prognostic value for anxiety disorders, depressive symptoms or even aggressive and hostile behaviour, despite the fact that they were coping well on the behavioural level.

After the end of cancer treatment (time 2), we found changes in the MSSB narratives of the affected group only. The siblings of the children with cancer presented a reestablished feeling of control and reduced avoidance of conflicts but still displayed dysregulative aspects more often than the control group. These children, who were coping behaviourally well with the situation and not showing manifestations of psychiatric disorders, clearly remained at risk $[12,13]$. Despite our multimethod longitudinal approach with a comparison group, our study comprises several limitations, mainly the small sample size. In future research, a detailed analysis of accompanying risk factors, as well as an analysis of long-term effects in order to screen for high- and low-risk children, using diverse methods of assessment, would be of interest. In addition, taking into consideration the concept of posttraumatic growth within children seems highly relevant [14]. In summary, our results showed that parents did not observe particular symptoms in their children, although the MSSB stories demonstrated significant differences between the two groups and - in the affected group-over time. These findings should raise our awareness for the often so well functioning siblings of children with cancer, who are actually in need of attention and of a sensitive understanding of their emotional challenges. Even psychological support at a low frequency may be a very helpful tool in fostering their coping strategies, with the aim of preventing later psychiatric pathology.

Conflict of interest The authors declare that they have no conflict of interest.

Funding This work was supported by the "Schweizerische Arbeitsgemeinschaft für Klinische Krebsforschung" and the "Deutsche José Carreras Leukämie-Stiftung”.

\section{References}

1. Alderfer MA, Long KA, Lown EA et al (2010) Psychosocial adjustment of siblings of children with cancer: a systematic review. Psychooncology 19:789-805

2. Houtzager BA, Grootenhuis MA, Last BF (1999) Adjustment of siblings to childhood cancer: a literature review. Support Care Cancer 7:302-320

3. Wilkins KL, Woodgate RL (2005) A review of qualitative research on the childhood cancer experience from the perspective of siblings: a need to give them a voice. J Pediatr Oncol Nurs 22:305-319

4. Weber M, von Klitzing K (2004) Story stem evaluation in clinical practice with young children. Prax Kinderpsychol Kinderpsychiatr 53:333-346

5. Emde RN, Wolf D, Oppenheim D (2003) Revealing the inner worlds of young children: the MacArthur Story Stem Battery and parent-child narratives. Oxford. Oxford University Press, New York

6. Emde RN (2007) Engaging imagination and the future: frontiers for clinical work. Attach Hum Dev 9:295-302

7. Warren S, Oppenheim D, Emde RN (1996) Can emotions and themes in children's play predict behavior problems? J Am Acad Child Adolesc Psychiatry 35:637-644

8. Goodman R (1999) The extended version of the Strengths and Difficulties Questionnaire as a guide to child psychiatric caseness and consequent burden. J Child Psychol Psychiatry 40:791-799

9. Juen F, Guggemos A, Engelmann L, Diesselhorst V, Di Gallo A (2013) How children who's siblings are diagnosed with cancer experience and regulate the disease. Prax Kinderpsychol Kinderpsychiatr 62:491-504

10. Sloper P (2000) Experiences and support needs of siblings of children with cancer. Health Soc Care Community 8:298-306

11. Buchsbaum H, Toth S, Clyman R, Cicchetti D, Emde RN (1992) The use of a play narrative story stem technique with maltreated 
children: implications for theory and practice. Dev Psychopathol 4: 603-625

12. Prchal A, Landolt MA (2012) How siblings of pediatric cancer patients experience the first time after diagnosis: a qualitative study. Cancer Nurs 35:133-140
13. Nolbris M, Enskar K, Hellstrom AL (2007) Experience of siblings of children treated for cancer. Eur J Oncol Nurs 11:106-116

14. Tedeschi R, Calhoun LG (1995) Trauma and transformation: growing in the aftermath of suffering. Sage Publications Ltd, Newbury Park 